\title{
Analysis of the Construction of Foreign Literature Resources in University Libraries
}

\author{
Min Feng \\ Shandong University of Arts, Library, Jinan Shandong, China 250014 \\ 75668299@qq.com
}

Keywords: University Library; Foreign Literature; Resources Construction

\begin{abstract}
Foreign language literature resources in University libraries are an important part of library literature resources, which reflect the most advanced information and trends in terms of science, politics, economy, culture and other fields. However, actual use is not optimistic. The low utilization rate and the irrational construction of literature resources are common in university libraries. Therefore, we must pay attention to these problems and strive to improve them so that the foreign language literature resources in universities can play its biggest role in teaching and research.
\end{abstract}

\section{Introduction}

In recent decades, with the continuous development of major universities, the development of libraries has also received soaring attention, and the foreign language literature resources with strong timeliness have become an important part of each university library collection. Foreign language documents can help teachers and students understand the latest scientific and technological information, frontiers of disciplines, and research results of developed countries. They also provide scientific research topics and materials for innovative achievements which is very significant to guide teaching and scientific research. However, according to the actual situation, there are still many problems in the construction of foreign language literature resources in university libraries. Therefore, under the circumstances of limited funds for library purchases, how to construct foreign language literature resources effectively and improve the utilization of foreign language resources is the main problem we are currently facing.

\section{Foreign Literature Resources Types}

With the development of the times, the library's documentation resources have long been not limited to paper resources. According to different classification methods, it can be divided into a great deal of types. For example, according to different storage carriers, foreign language document resources can be divided into paper resources and electronic media resources; according to different publishing methods, foreign language document resources can be divided into books, periodicals, and papers. And so on; according to the different sources of resources, library foreign language literature resources can be divided into literature resources obtained through paid sales, such as databases, e-books, free access resources, such as open and accessible resources, trial databases, personal gifts donated, as well as literature resources obtained through inter-library resource sharing.

The Basic Principles and Importance of the Construction of Foreign Literature Resources in University Libraries

The Basic Principles of the Construction of Foreign Literature Resources in University Libraries. The resource construction of foreign language literature in university libraries should be based on their own actual situation, combined with the long-term development strategy formulated by the Library, the borrowing rate of actual resources and readers' needs. The quantity and quality should be considered when purchasing with a small amount of funds. At the same time, we have to 
ensure that selected foreign language documentation resources meet the requirement of both students and teachers. Therefore, the foreign language literature resources should be practical, economical, authorized and can be preserved and have special features.

The Importance of the Construction of Foreign Literature Resources in Colleges and Universities. As an indispensable part of the university library's documentation resources, foreign language documents reflect the advanced ideas and scientific and technological information of all countries in the world, especially the developed countries. It is our gateway to learn about foreign cultures, accessing advanced scientific research results, and mastering the direction of science and technology development, which can also provide important resources for the scientific research and academic innovation of our university's scientific research personnel. Second, foreign language documents are also good language learning tools that can help college students learn to improve their foreign language proficiency and obtain foreign cultural knowledge. As China continues to expand and deepen its opening to the outside world, the exchanges between domestic universities and foreign universities have become increasingly close, and the English level of foreign language of teachers and students in universities has also continued to increase. We all expect to obtain more information on foreign life, culture, science and education. Therefore, the construction of foreign language literature resources in university libraries also highlights its importance.

\section{Problems Encountered in the Construction of Foreign Language Literature Resources in Universities}

Shortage of funds for book purchase and unreasonable resource construction. Foreign language documents are often expensive and not limited to English language. Most previous university libraries have paid little attention to the purchase of foreign documents. In recent years, they have increased purchases year by year. There are many document resource providers available for general literature ordering in libraries, but currently the market for imported foreign language literature resources in China is relatively small, resulting in a great influence on foreign language document resource providers to the market, and they have pricing power for products. The decision on the type of product introduction has led to the situation that university libraries are facing problems such as the lack of funding for purchase of foreign documents and the monotonous nature of resource purchases. According to statistics, the purchase costs of foreign language documents in university libraries account for a large part of the total book purchase expenses. The large sums of money spent on library resources in universities bring huge challenges to foreign language construction. In addition, the purchase of foreign language resources is not reasonable enough, the selectivity is small, the duplication degree is high, and the purchase repetition rate among the libraries of various universities is also very large. Even some of the special book offerings are used books, which are old and outdated without collection value. These problems are the main reasons for the unreasonable structure of the collection of foreign language resources, which is a basic problem that exists in every university library, and it is also an issue that we urgently need to solve.

No Professional Foreign Language Document Resource Construction Team. In recent years, with the change of cognition, all universities have paid more and more attention to the construction of library foreign language literature resources, but the results seem to be small. Only by developing scientific and reasonable collection development strategies and procurement standards for foreign language literature resources can the entire collection resources be systematic, complete, and objective. If there is no clear and specific positioning of foreign language literature resources, interviewers will be at a loss. At the same time, the preparation of university library staff can not keep up, there is almost no special staff engaged in the construction of foreign language documentation resources. In order to save time, some libraries ask staffs engaged in Chinese documentation resources to deal with foreign language book cataloging and processing. However, due to insufficient knowledge in English, they cannot play their roles very well. Without professional services, readers' needs cannot be met. All these have greatly affected the construction of foreign language literature resources. 
The Overall Utilization Rate of Foreign Literature Resources Is Not High. The low utilization rate of foreign documents is reflected in the fact that there are quite a few zero-utilization foreign books in each university library. There are many reasons leading to this situation. For example, the library does not have corresponding promotional activities. Both teachers and students do not even know there are foreign language documents suitable for their own professionalism in the library, resulting in low utilization rates. In addition, the major groups of foreign language literature resources in universities are teachers and graduate students. Most of the readers rarely borrow foreign language documents because of their low foreign language level. Third, the quality of foreign language literature resources is uneven and varied. The lack of services for foreign documents is also a reason for low utilization. The above reasons lead to unsatisfactory use of foreign language literature resources, and low utilization rate will also cause serious waste of resources.

Lagging Behind Foreign Literature Resources Co-construction and Sharing Construction. At present, major university libraries do not have a clear plan for resource construction. Without policies, they will be stagnant and explore blindly. There is no way to share resources, even in a highly informative era. Many universities in similar disciplines purchase the same foreign language resources, and the resource duplication rate is very high, which results in a waste of funds.

\section{Suggestions on Construction of Foreign Literature Resources}

The fundamentals of the library are books and all literature resources, which are also the prerequisite for the library to carry out all service work. As an important part of the library's literature resources, the construction of foreign language literature resources is still in its infancy. Therefore, in order to improve the collection resources of university libraries, the construction of foreign language literature resources must be put on the agenda. Here are some suggestions:

Try the Utmost to Raise Funds in Various Ways to Increase the Collection of Foreign Language Literature. There are limited funds for book purchase in university libraries, but most of the foreign language literature resources are relatively expensive, which requires other ways to raise funds in various ways. On the one hand, we can report to higher supervisors, trying tireless efforts to raise funds. On the other hand, a certain amount can be appropriately drawn from the teaching and research funds for the purchase of books. Books especially recommended for purchase by some professional teachers can be applied to the school for special funds. Only when all parties actively raise funds can we increase the number of foreign language documents reasonably and effectively.

Doing a Good Job of Procurement of Foreign Documents. Foreign language literature procurement is more professional than ordinary book procurement, especially in the case of shortage of books. How to use a limited amount of money to purchase high quality and quantity of foreign language resources is a big problem. This requires the editing and editing department to fully understand the discipline construction and development direction of the school, combine the library collections, and formulate a set of procurement plans to strive to maximize the use of limited funds and do its utmost to meet the foreign language resource requirements of the majority of readers in the school. At the same time,we must also communicate with foreign publishers to obtain the most up-to-date information, and then combine the opinions of the teachers of the secondary colleges on the purchase of books to select professional books that meet the discipline of the university and increase the use of foreign books.

Strengthen the Publicity of Library Foreign Language Literature Resources. With the increase in the purchase of foreign documents, many universities have established independent external libraries. However, readers' borrowing volume has always been unsatisfactory, which has resulted in a great waste of foreign language documentation resources. Therefore, it is also important to promote foreign literature collections in the library to attract readers' attention. University libraries can start publicity in various aspects. For example, they can issue lists of holdings to secondary colleges, introduce foreign language library collections through library activities, and cooperate with foreign language teaching departments to allow teachers to move 
classes into libraries for them to understand more about the collection of foreign language resources.

Combine Traditional Service and New Service. Lots of people think that the service of a university library is only borrowing from machinery, waiting for the readers to come to the door. But in fact, with the development of modernization of information, the library has long changed the traditional obsolete service. We should remain the traditional methods and also actively promote information by combining modern methods such as websites, We Chat, and electronic platforms to take the initiative to push message, recommend new books, borrow and return independently, automatic search etc. so as to let readers be aware of the resources in time and ensure convenient borrowing and returning. In addition, professionals are arranged to assist readers who are not so good at foreign languages to conduct data retrieval and translation work, and to guide readers to make better use of foreign language materials so that readers can truly feel the benefits of foreign language literature resources.

Strengthen the Cooperation and Exchange Among the Libraries of Various Universities And Achieve the Co-construction and Sharing of Resources. Each university library has limited funds for books, but the price of foreign language literature resources is not low, and it is impossible to use all the funds for the purchase of foreign documents. In this case, it is impossible for the collections of individual university to cover all aspects and can satisfy all the needs. In order to solve this problem, the most direct and effective way is to realize the co-construction and sharing of resources between university libraries. This requires the consensus between libraries of various universities, the integration of the foreign language literature resources of each library, and the establishment of a resource sharing platform to achieve mutual benefit and common development. Through these measures, it is possible to greatly save the funding for books purchased by various university libraries and to make buying more reasonable and convenient. This can best satisfy the needs of teachers and students readers of foreign language literature.

\section{Conclusion}

In summary, we can see that the construction of foreign language literature resources in university libraries is a long and complicated process. In the process of construction, there are still many problems to be solved and difficulties that need to be overcome. This requires all universities to increase their attention to the construction and management of library foreign language literature resources, strive to change the existing state, so that the limited foreign language literature resources have the greatest effect on the school's teaching and research.

\section{References}

[1] L.J.Gu: New Ideas on the Development and Utilization of Foreign Literature Resources in University Libraries [J], Journal of Library Science in China, (2000) No.2. (In Chinese)

[2] M.X. Dong: Present Situation and Development Approach of Foreign Language Documentation Resource in University Libraries[J], Information Exploration, (2009) No.3. (In Chinese)

[3] H.Yang: Research on the Construction of Foreign Literature Resources in Public Libraries[J], Library Development, (2011) No.11. (In Chinese)

[4] J.Zhou, J.Su and J.X.Zeng: The Development and Thinking of the Next Generation Digital Libraries[J], Library and Information Service, Vol. 57 (2013) No.8, p. 35. (In Chinese)

[5] L.Zhong: The Survey and Revelation of the Library Characteristic Resources in Colleges and Universities of Hong Kong[J], Researches in Library Science, (2013) No.8, p.36. (In Chinese) 